\title{
Ocular Problems among Video Display Terminal Users in a Software Company of Sector V, Kolkata
}

Rivu Basu¹, Aprajita Dasgupta²

${ }^{1}$ Assistant Professor, R G Kar Medical College; ${ }^{2}$ Professor, Department of Preventive and Social Medicine, All India Institute of Hygiene and Public Health, Kolkata, West Bengal - 700098

\begin{tabular}{|c|c|c|c|c|c|c|c|}
\hline Abstract & Introduction & Methodology & Results & Conclusion & References & Citation & $\underline{\text { Tables / Figures }}$ \\
\hline \multicolumn{8}{|c|}{ Corresponding Author } \\
\hline \multicolumn{6}{|c|}{$\begin{array}{l}\text { Dr Rivu Basu, 3, Gauranga Mandir Road, Kolkata-700086 } \\
\text { E Mail ID: rivubasu83@gmail.com }\end{array}$} & & 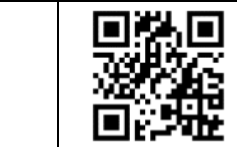 \\
\hline
\end{tabular}

\section{Citation}

Basu R, Dasgupta P. A Cross Sectional Study on Ocular Problems among Video Display Terminal Users in a Software Company of Sector V, Kolkata. Indian J Comm Health. 2020;32(4):631-636. https://doi.org/10.47203/IJCH.2020.v32i04.004

Source of Funding: Nil Conflict of Interest: None declared

\section{Article Cycle}

Received: 28/10/2020; Revision: 15/11/2020; Accepted: 21/12/2020; Published: 31/12/2020

This work is licensed under a Creative Commons Attribution 4.0 International License.

\section{Abstract}

Background: Video Display Unit use and Information Technology creates a host of problems like Ocular Problems and Work Related Musculo Skeletal Problems. Many experience visual symptoms including eyestrain, headaches, ocular discomfort, dry eye, diplopia and blurred vision either at near or when looking into the distance after prolonged computer use. Very few and sporadic studies have been done in this part of the world especially in India, to address the issue in all its scope. Aim \& Objective: To find out the proportion of different ocular problems among the study population and to find out the association of their ocular problems with the socio-demographic, work related and ergonomic factors. Materials and methods: It was an institution based, cross sectional, analytical epidemiological study and was conducted over one-year period. The study population comprised of persons working with Video Display Terminals. A predesigned, semi-structured instrument for elaborating the socioeconomic, lifestyle related and a few job-related health behaviors were used. Combination of few instruments to elicit different morbidities like and many ergonomic checklists to evaluate office workspace were also used. Results: Of the total $79.1 \%$ had any kind of ocular problems currently, with around $65 \%$ of them reporting to be having problem constantly in the last 12 months. Headache (63.6\%) seemed to be the most important problem, followed by Eye fatigue (52.4\%). Repetition of work and poor ergonomic practices turned out to be the statistically significant factors. Increased Years of working and female sex were also found to be important factors. Screen Character was found to be the most important risk factor of eye problems. Conclusion: A simple model was proposed where interaction of Individual factors and factors related to workstation was identified as the main culprit, which exaggerated by the repetition of work.

\section{Keywords}

Ergonomics; Computer Vision Syndrome

\section{Introduction}

Video Display Unit use and Information Technology are revolutionizing daily lives. However, it has created some expensive and long-term problems. A host of problems like Work Related Musculo-Skeletal
Disorders (WRMSDs) (1), ocular problem are already proved morbidities associated with VDT (Video Display Terminal) use.

These problems are not only are taking a huge magnitude as the VDT use is increasing, but they are 
significantly affecting the economy too. A few years back, before the advent of computers, the office work involved a range of activities, including typing, filing, reading, and writing etc. All these activities differed from each other and needed different types of posture and vision, thus having breaks interspersed between activities. With the computer all these activities were combined and needed no change of posture or vision of the user from his desktop. It certainly improved the quality of the work and efficiency but caused a host of ocular problems that stem from using a computer especially to the eyes. All these symptoms collectively referred to as computer vision syndrome (CVS) $(2,3,4)$ which comprised of ocular surface abnormalities or accommodative spasms and/or extra-ocular (ergonomic) etiologies due to improper posture such as neck and upper back pain and headache. A review of CVS, Thomson (5) indicated that up to $90 \%$ of computer users may experience visual symptoms including eyestrain, headaches, ocular discomfort, dry eye, diplopia and blurred vision either at near or when looking into the distance after prolonged computer use. These symptoms result from the individual having insufficient visual capabilities to perform the computer task comfortably.

Few studies $(6,7)$ have been done in this part of the world especially in India, to address the issue in all its scope. VDT use, as it is entering the Indian Scenario in a big way, should be a matter of utmost importance to gather necessary evidence for policy making, so that it can be defused before the explosion occurs.

\section{Aims \& Objectives}

1. To find out the proportion of different ocular problems among the study population.

2. To find out the association of their ocular problems with the socio-demographic, work related and ergonomic factors.

\section{Material \& Methods}

Study type: It was an institution based, cross sectional, analytical epidemiological study. This was a part of multi objective study done in the same area, the first being done to identify Musculo skeletal disorders among the workers (1).

Study Population, area, duration: It was conducted over one-year period starting from in Bidhannar, or Salt Lake City as it is popularly called, is a planned satellite township and a hub of Information technology in Kolkata (Sector V). The company selected (name withheld under obligation) for this study mainly works for Government Projects with other projects too, with mostly data processing and software development as their job. They also do Business Process Outsourcing. The study population comprised of persons working with Video Display Terminals.

Inclusion and exclusion criteria: Those who gave consent to participate in the study and worked in the current job for at least 6 months were included in the study.

Sample size calculation: A. K. Sharma et al of Department of Community Medicine, Lady Hardinge Medical College, New Delhi (8) in a study on VDT users in the National Capital Region observed the proportion of health problems among VDT users as high as 93\%. Thus, with Expected Proportion (P) $=93 \%$, Relative precision $(\mathrm{I})=5 \%$, Desired confidence limit $=95 \%$, the Sample size came out to be 151 . To it total of $10 \%$ attrition was added, so it became 165 . So, the minimum sample size required is 165 .

Sampling technique and strategy for data collection: The company was selected purposively. After taking necessary permission from the authority through proper channel, the employers were explained about the study by distributing pamphlets asking for voluntary participation, assuring confidentiality of data and anonymity. Among them 242 persons were willing to take part in the study, and all of them were working for 6 months or more in their current positions. So, it was decided that everyone shall be recruited for ethical consideration. They were given numbers accordingly and tentative dates for their examinations, to manage with the time-schedule and work pressure of employees as also the time restraint of the researcher. For the same reason it was also decided that they shall be informed about the poor ergonomic practices and helped in adjusting their ergonomic posture after the total exercise is over in a single session.

15 subjects either left the company or did not participate even after consenting initially. Thus, dropout rate was $6.2 \%$. The 227 remaining population duly participated in the study. While entering data it was found that 21 of them have not filled the self-report form correctly/completely. So, they were also eliminated from the analysis. Thus, analysis was done with 206 subjects, which was above the targeted 165 samples. [Figure 1]

Study tool: A predesigned, semi-structured instrument for elaborating the socio-economic, 
lifestyle related, and a few job-related health behaviors were used. The ocular symptoms were asked as well as the combination of few instruments to elicit different morbidities like and many ergonomic checklists to evaluate office workspace for ocular problems were also used. The questionnaire was judged by a group of experts of AllH\&PH where they made necessary corrections to enhance face validity, content validity and consensual validity. After permission from the company, before the actual interviews, a few consenting professionals of that company were selected. They were administered the questionnaire. They were asked about the places they had problems filling up/answering. It also corrected many of the comprehensibility problems of the questionnaire. Then the questionnaire was finalized.

The ergonomic factors were scored as good or bad and then composite scored were made from them according to median splits into good or bad to avoid misclassification bias.

\section{Results}

Thus, $79.1 \%$ had any kind of ocular problems currently, with around $65 \%$ of them reporting to be having problem constantly in the last 12 months. Headache (63.6\%) seemed to be the most important problem, followed by Eye fatigue (52.4\%). [Table 1]. Repetition of work and poor ergonomic practices turned out to be the statistically significant factors. Increased Years of working and female sex were also found to be important factors, though statistically not significant. [Table 2]

Character of Screen seems to be the most important ergonomic factor for the diseases. [Table 3]

\section{Discussion}

Occurrence of ocular symptoms: The Comparison of the results of the study with others are given in the table 4 . Thus, the magnitude seems to be increasing with years

Factors causing ocular problems: Factors like poor screen character, direct light on the screen, not placing the monitor between rows of bright lights, light level behind and to the sides of the monitor all play important roles in determining these symptoms, as well as good lighting of the cubicle and minimization of glare from the environment were assessed here. All of them except one (non placement of screen between rows of overhead lights) came to be risk factors here, in concordance with other studies $(9,10,11,12,13)$.
Here female sex $(O R=1.1)$ and increased ages $(\mathrm{OR}=1.8)$ were risk factors for the development of ocular symptoms, as is mentioned in other literatures also, $(14,15,16,17,18)$ as is repetition of work, which had emerged as a significant risk factor in this study. But however, the risk increase with increased years of job is not so consistent here. Use of spectacles were not considered here, that may be be confounding the results, that needs further research.

Models: Thus, the morbidities are coming from a complex interaction of the various factors mentioned. It should be borne in mind that a very simple model proposed here. [Figure 2]

\section{Conclusion}

Thus, from this study a few facts should be pointed out safely. The extensive use of computers or VDTs has its adverse effects on health. The Ocular problems along with risk factors like poor ergonomic practices, the individual factors, the organizational factors Has been extensively mentioned in Western Literature. People may argue whether in a country like India, this is something of Public Health importance, and this is true, India has, at this moment other priorities. But as mentioned in the beginning, with the current economic growth rate in India, VDT is to be used by a greater number of Indians in near future. Keeping that in mind, the evidence gathering should begin now, learning lessons from the West, with this aim, this study was conducted.

\section{Recommendation}

Thus, this study is like a looking glass into the complex world of office ergonomics. Researches must be targeted for this, customized for the country, as this will help generate better human resources, lesser attrition, good value system of the companies, and help in the growth of the country. This will impact long term productivity and help in generating policy decisions in occupational field.

\section{Limitation of the study}

Study design: This study is essentially a cross sectional study and has got all the pitfalls of such a design. Though prevalence can be measured in this study, but the risk ratio obtained is more of an unmatched Odd's Ratio, and it is never as good as the OR of a case control study, or Relative risk of a cohort study. Besides, a very important factor, i.e. temporal relationship could not be elicited in this kind of study. 
Exposure ascertainment: The measurement of exposure is a potent source of bias in the study as the ergonomic postures or factors measured are filled by the employees themselves. Median splits were done to make the misclassification a non-differential one, still it is difficult to be really sure, that it really does not exist. This basically gives a problem to the denominator.

Outcome measurement: By not taking any pathological proof, or radiological evidence for the diseases i.e. by not doing any diagnostic tests, the outcomes under study were not valid. But taking a symptomatic approach increased the scope of the study maybe that was the reason for obtaining such high prevalence.

Induction time: Another common problem with occupational epidemiology is the induction time of onset of diseases. Only after knowing that, the population at risk should be considered, as before that time, a person exposed is not under risk of developing the disease. But unfortunately, such a measure is not available in the literature.

The model: A very important factor was missed in this study due to its complex nature and interactions; it was not considered-i.e. stress. Stress is the cause of many of the diseases, as mentioned in the review of literature. That was not measured.

Probably in future, better, multidisciplinary research can be done to gather stronger evidence for policy making.

\section{Relevance of the study}

This study adds to the prevalence and risk factors of computer vision syndrome in India, regarding which studies are rare in India.

\section{Authors Contribution}

RB: Planning, Survey, Analysis, Manuscript writing; $A D$ : Planning, Manuscript writing

\section{References}

1. Basu R, Dasgupta A, Ghosal G. Musculo-skeletal Disorders among Video Display Terminal Users: A Cross-Sectional Study in a Software Company, Kolkata. J Clin Diagn Res JCDR. 2014;8(12):JC01-04.

2. Lee K, Swanson N, Sauter S, Wickstrom R, Waikar A, Mangum M. A review of physical exercises recommended for VDT operators. Appl Ergon. 1992;23(6):387-408. doi: 10.1016/0003-6870(92)90370-b.

PMID: 15676884. [PubMed]

3. Wimalasundera S. Computer vision syndrome. Galle Med J. 2009 28;11(1):25-9.

4. Diagnosing and Treating Computer-Related Vision Problems [Internet]. Elsevier; 2003 [cited 2020 Dec 25]. Available
[Video Display Terminal...] | Basu R et al https://linkinghub.elsevier.com/retrieve/pii/B9780750674 041X50011

5. Thomson WD. Eye problems and visual display terminals-the facts and the fallacies. Ophthalmic Physiol Opt. 1998 Mar;18(2):111-9. PMID: 9692030.[PubMed].

6. Computer vision syndrome: A review Bali J, Neeraj N, Bali RT - J Clin Ophthalmol Res [Internet]. Available from: https://www.jcor.in/article.asp?issn=23203897; year $=2014$; volume $=2$; issue $=1 ;$ spage $=61 ;$ epage $=68$;au last=Bali [cited 2020 Dec 25].

7. Ocular problems of computer vision syndrome: Review Raja AM, Janti SS, Chendilnathan C, Adnan M - J Mahatma Gandhi Inst Med Sci [Internet]. Available from: https://www.jmgims.co.in/article.asp?issn=09719903; year $=2015$; volume $=20$;issue $=2 ;$ spage $=134$; epage $=13$ 6;aulast=Raja [cited 2020 Dec 25].

8. Sharma AK, Khera S, Khandekar J. Computer related health problems among information technology professionals in Delhi. Indian J Community Med. 2006 Jan 1;31(1):36.

9. Juslén HT, Wouters MC, Tenner AD. Lighting level and productivity: a fieldstudy in the electronics industry. Ergonomics. 2007;50(4):615-24. doi: 10.1080/00140130601155001. PMID: 17575718. [PubMed].

10. Sa EC, Ferreira Junior M, Rocha LE. Risk factors for computer visual syndrome (CVS) among operators of two call centers in São Paulo, Brazil. Work. 2012;41Suppl 1:3568-74. doi: 10.3233/WOR-2012-0636-3568.

PMID: 22317263. [PubMed].

11. Ranasinghe $P$, Wathurapatha WS, Perera YS, Lamabadusuriya DA, Kulatunga S, Jayawardana N, Katulanda P. Computer vision syndrome among computer officeworkers in a developing country: an evaluation of prevalence and risk factors. BMC Res Notes. 2016 Mar 9;9:150. doi: 10.1186/s13104-016-1962-1. PMID: 26956624; PMCID: PMC4784392.[PubMed]

12. Office Ergonomics: A Review of Pertinent Research and Recent Developments - Jay L. Brand, 2008 [Internet]. Available from: https://journals.sagepub.com/doi/abs/10.1518/15572340 8x342871 [cited 2020 Dec 25].

13. Assefa NL, Weldemichael DZ, Alemu HW, Anbesse DH. Prevalence and associated factors of computer vision syndrome among bank workers in Gondar City, northwest Ethiopia, 2015. Clin Optom (Auckl). 2017 10;9:67-76. doi:10.2147/OPTO.S126366. PMID: 30214362; PMCID: PMC6095566.[PubMed]

14. Branda. Prevalence of Occupational Diseases in information Technology Industries in Goa. Indian J Occup Environ Med. 2004; 1;8(1):30.

15. A community-based study of asthenopia in computer operators Bhanderi DJ, Choudhary S, Doshi VG - Indian J Ophthalmol [Internet]. Available from: https://www.ijo.in/article.asp?issn=03014738; year $=2008$; volume $=56$; issue $=1$; spage $=51$; epage $=55$; a ulast=Bhanderi [cited 2020 Dec 25]

16. Dehghani A, Tavakoli M, Akhlaghi M reza, Beni AN, Eslami F. Prevalence of ocular symptoms and signs among professional computer users in Isfahan, Iran. J Res Med Sci. 2008 24;13(6):303-7. 
INDIAN JOURNAL OF COMMUNITY HEALTH / VOL 32 / ISSUE NO 04 / OCT - DEC 2020

17. Shrestha GS, Mohamed FN, Shah DN. Visual problems among video display terminal (VDT) users in Nepal. J Optom. 2011;4(2):56-62.

18. Computer Vision Syndrome Among Medical And Engineering Professionals Of India | International Journal of
[Video Display Terminal...] | Basu R et al Current Research [Internet]. Available from: https://www.journalcra.com/article/computer-visionsyndrome-among-medical-and-engineering-professionalsindia. [cited 2020 Dec 25].

\section{TABLES}

TABLE 1 THE FOLLOWING TABLE SHOWS THE FREQUENCIES OF DIFFERENT OCCULAR TROUBLES OF THE STUDY POPULATION ( $\mathrm{N}=\mathbf{2 0 6})$

\begin{tabular}{|l|l|}
\hline Trouble & Present (\%) \\
\hline Any Eye Trouble, including headache & $163(79.1)$ \\
\hline Eye Fatigue & $108(52.4)$ \\
\hline Dryness/itching of eyes & $56(27.2)$ \\
\hline Watering of eyes & $81(39.3)$ \\
\hline Others (diplopia, "dancing" etc) & $21(10.2)$ \\
\hline Headache & $131(63.6)$ \\
\hline
\end{tabular}

TABLE 2 DISTRIBUTION OCULAR SYSTEM TROUBLES WITH DIFFERENT VARIABLES ( $\mathbf{N}=206$ )

\begin{tabular}{|c|c|c|c|}
\hline Parameter & Total & Number having any ocular trouble(\%) & Odd's Ratio $(95 \% \mathrm{CI})$ \\
\hline \multicolumn{4}{|c|}{ (1) } \\
\hline $21-30$ & 121 & $98(80.9)$ & 1(reference) \\
\hline $31-40$ & 68 & $50(73.5)$ & $0.65(0.3-1.4)$ \\
\hline 41 and above & 17 & $15(88.2)$ & $1.8(0.4-12)$ \\
\hline \multicolumn{4}{|l|}{ Sex } \\
\hline Male & 112 & $88(78.6)$ & 1 (reference) \\
\hline Female & 94 & $75(79.8)$ & $1.1(0.6-2)$ \\
\hline \multicolumn{4}{|l|}{ Years of Working \# } \\
\hline lowest quartile $(<3)$ & 67 & $47(70.1)$ & 1 (reference) \\
\hline $25-50$ quartile (3-4) & 29 & $26(89.7)$ & $3.7(0.9-17)$ \\
\hline $50-75$ quartile (5-6) & 46 & $39(84.8)$ & $2.4(0.8-6.9)$ \\
\hline Highest quartile (>6) & 64 & $51(79.7)$ & $1.7(0.7-4)$ \\
\hline \multicolumn{4}{|l|}{ Repetitions } \\
\hline Present & 89 & $78(87.6)$ & $2.7(1.2-6)^{*}$ \\
\hline \multicolumn{4}{|c|}{ Ocular Ergonomic Score $\$$} \\
\hline poorer quartile $(<=2)$ & 118 & $105(89)$ & $4.2(2-8.6)^{*}$ \\
\hline better quartile $(>2)$ & 88 & $58(65.9)$ & 1 (reference) \\
\hline
\end{tabular}

\section{TABLE 3 ASSOCIATION OF OCULAR TROUBLE WITH DIFFERENT ADVERSE ERGONOMIC FACTORS}

\begin{tabular}{|c|c|c|c|}
\hline Parameter & $\begin{array}{l}\text { Adverse ergonomic } \\
\text { Practice ( } \mathrm{N}=206)\end{array}$ & $\begin{array}{l}\text { Ocular } \\
\text { Trouble (\%) }\end{array}$ & OR $(95 \% \mathrm{Cl})$ \\
\hline Screen character & 111 & $95(85.6)$ & $2.4(1.1-5)^{*}$ \\
\hline $\begin{array}{l}\text { Is your computer monitors placed at right angles to bright light } \\
\text { sources (windows, wall lamps, etc.)? }\end{array}$ & 125 & $101(80.8)$ & $1.3(0.6-2.7)$ \\
\hline $\begin{array}{l}\text { Is your monitor placed between rows of overhead light fixtures to } \\
\text { avoid reflections? }\end{array}$ & 80 & $56(70)$ & $0.4(0.2-0.9)$ \\
\hline $\begin{array}{l}\text { Is the light level behind and to the sides of your monitor similar to } \\
\text { the light level emitted from the screen? }\end{array}$ & 128 & $104(81.3)$ & $1.4(0.7-2.9)$ \\
\hline $\begin{array}{l}\text { Is your cubicle so located so that they are evenly lit by overhead or } \\
\text { wall lights? }\end{array}$ & 81 & $66(81.5)$ & $1.3(0.6-2.7)$ \\
\hline Is reflected glare from your environment minimized? & 165 & $133(80.6)$ & $1.5(0.6-3.6)$ \\
\hline Total number of persons having Ocular Trouble & & 163 & \\
\hline
\end{tabular}


TABLE 4: TABLE TO SHOW COMPARISON OF OCULAR MORBIDITIES OF DIFFERENT STUDIES WITH THE PRESENT STUDY

\begin{tabular}{|c|c|}
\hline Study & Occurrence of symptoms \\
\hline India, 2005 (14) & Visual fatigue is the predominant complaint. \\
\hline India, 2003 (15) & $\begin{array}{l}\text { Among the } 419 \text { subjects studied, } 194 \text { (46.3\%) suffered from asthenopia during or after work on } \\
\text { computer. }\end{array}$ \\
\hline India, 2005 (8) & Visual problem was found in $76 \%$ of the population \\
\hline India, 2005 (14) & Visual fatigue is the predominant complaint. \\
\hline Iran, 2008 (16) & $\begin{array}{l}\text { Among VDUs, burning eyes and tearing, dry eye, asthenopia, and musculoskeletal pain was } \\
\text { statistically significant. }\end{array}$ \\
\hline Nepal, 2011 (17) & $\begin{array}{l}\text { Ocular changes were reported in } 92.1 \% \text { of the total subjects. Most common symptoms were tired } \\
\text { eye and headache. }\end{array}$ \\
\hline Sri Lanka, 2016 (11) & The 1-year prevalence of CVS in the study population was $67.4 \%$ \\
\hline India, 2017 (18) & $82.68 \%$ among medical and engineering students \\
\hline Current Study & $\begin{array}{l}\text { A huge number of persons are suffering from any ocular }(58.8 \%) \text { disorders. Among ocular } \\
\text { problems, headache was the most common }(63.6 \%) \text {, followed by eye fatigue }(52.4 \%) \text {, watering of } \\
\text { eyes }(39.3 \%) \text {. }\end{array}$ \\
\hline
\end{tabular}

\section{Figures}

FIGURE 1: THE SAMPLING FLOW OF THE STUDY

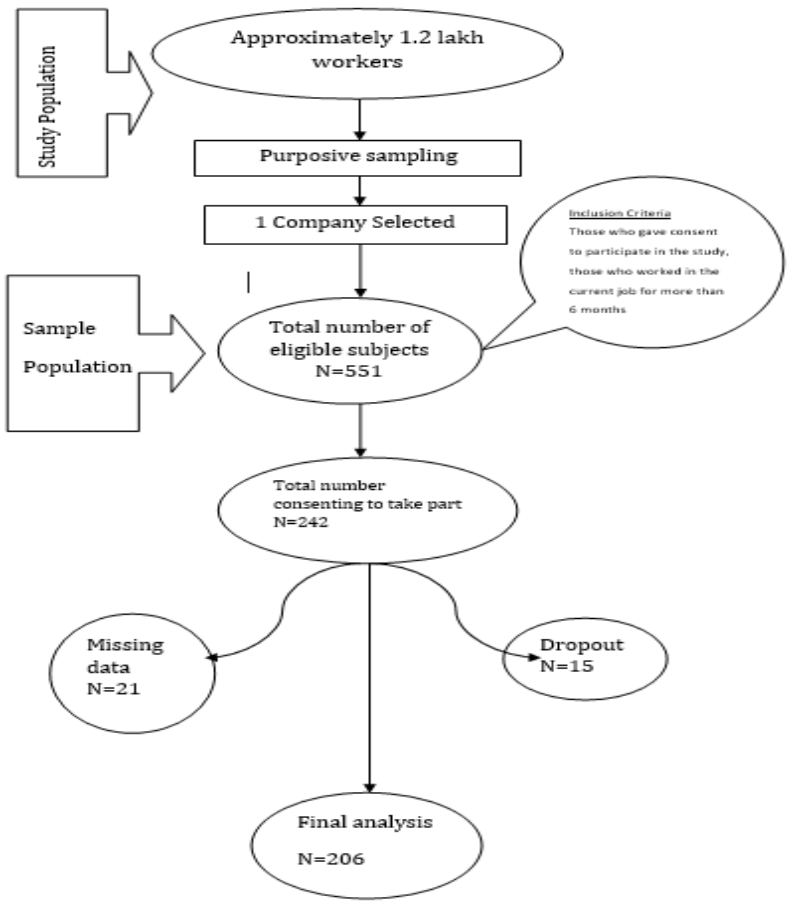

FIGURE 2: THE SIMPLE CAUSAL MODEL PROPOSED IN THE STUDY

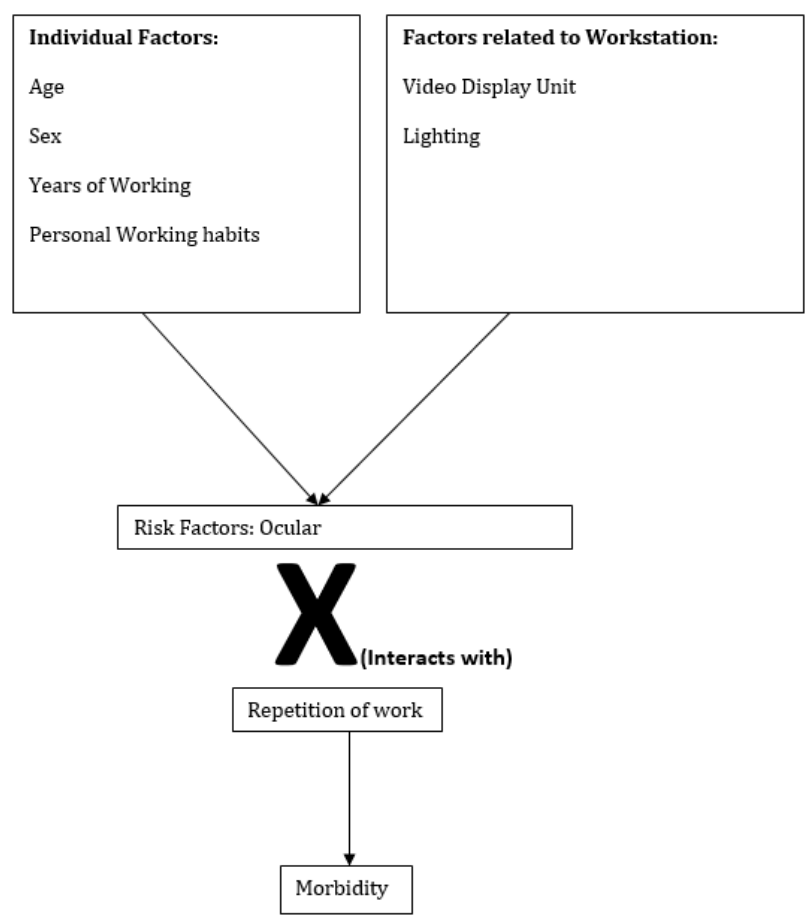

